\title{
Advanced ceramics - the new frontier in modern-day technology: Part I
}

\author{
by W.R. Matizamhuka
}

\section{Synopsis}

Advanced ceramics have demonstrated phenomenal performance under severe conditions in a number of areas, including wear-related applications, transport, energy and environment, health, high-temperature, and electronic applications. However, they have yet to attain the long-expected broad market penetration, especially on the African continent. The growth of advanced ceramics usage has been hindered mainly by low reliability, brittleness, unfamiliarity to potential users, redesign requirements, and the high cost of components. Research and development has led to significant improvements in the properties of advanced ceramics. The paper features some background on the development of advanced ceramics, and a review of the properties and application areas, with the aim of providing insight into the potential areas in this field where the South African science and engineering community could invest time and resources.

\section{Keywords}

advanced ceramics application, engineering materials, superior performance, technological applications.

\section{Introduction}

Advanced ceramics are an integral part of modern technology. Most of these products play crucial functions 'behind the scenes' in a number of applications in everyday life. They usually offer superior performance that cannot be replicated easily by other materials (Riedel, 2013). Advanced ceramics today play a key role in technologies such as energy and the environment, transport, the life sciences, and communication and information technology (Greil, 2002).

The terminology for defining this type of ceramics differs from continent to continent (Kulik, 1999). In the Japanese literature it's normally referred to as 'fine' ceramics, and in American literature as 'advanced' or 'technical' ceramics (Kulik, 1999). In the European context the term 'technical' ceramics is more frequently used (Kulik, 1999). A further classification, depending on the use, is common in the UK, where the term 'technical ceramics' is further subdivided into functional ceramics to refer to electronic applications and structural ceramics to refer mostly to mechanically loaded components (Kulik, 1999).

Advanced ceramics possess unique properties that cannot be obtained in conventional materials, such as high refractoriness and hardness, low density, low coefficient of thermal expansion (CTE), and higher working temperatures (can maintain good mechanical properties at high temperatures). Moreover, there are reports which have proven that the cost of producing ceramic materials is lower compared to metallic materials, and raw material reserves for ceramics are abundant (Kulik, 1999). Resources for the production of metals and their alloys are dwindling, and the continuously increasing demand for engineering products requires alternative materials to be identified. Over the past few decades advanced ceramics have made inroads in a number of critical applications in everyday life. It is noteworthy to mention here that without sparkplugs made of alumina $\left(\mathrm{Al}_{2} \mathrm{O}_{3}\right)$ ceramic, vehicle technology would not be so advanced, moreover metallurgy would not be so reliable without refractories (Kulik, 1999). These are the hard facts behind commonplace products that we normally take for granted.

Although ceramics play a crucial role in a number of technologies due to their unique combination of properties, it must be noted that as structural materials they still face stiff competition from cheap metals, alloys, and composites (Kulik, 1999). Thus the major barriers to the broad application of advanced ceramic materials include the lack of specifications and databases, high scale-up costs, and lack of repair methods (Freitag and Richerson, 1998). However, over the years a lot of progress has been made to alleviate these deficiencies through new material discoveries, improvements in properties, and improved design methods (Freitag and Richerson, 1998).

* Department of Metallurgical Engineering, Vaal University of Technology, South Africa.

(C) The Southern African Institute of Mining and Metallurgy, 2018. ISSN 2225-6253. Paper received Jul. 2017; revised paper received Feb. 2018. 


\section{Advanced ceramics - the new frontier in modern-day technology: Part I}

\section{World market for advanced ceramics}

The term 'advanced ceramics' was coined in the 1970s to designate a new category of engineering materials that were to drive new technologies into the 21 st century (Charreyron, 2013). Since then there has been phenomenal growth in the technological advancement of these materials. A report from Research and Markets projected the advanced ceramics market to reach US $\$ 10.4$ billion by 2021 , growing at a compounded annual growth rate (CAGR) of $6.5 \%$ (Charreyron, 2013). This growth is attributed to the increasing use of advanced ceramic materials as alternatives to metals and plastics, with key drivers being the medical, electronics, and transport industries. The analog-to-digital shift in consumer products has seen massive growth in electronic device content in a number of applications. For instance, liquid crystal displays (LCDs) replaced cathode ray tubes and DVDs replaced VHS tapes and players. This basically points to significant growth for ceramic capacitors and other ceramic electronic components. The largest share of the market has always been in the electronics industry, representing approximately more than $70 \%$ of production, but positive and negative shifts are expected according to changes in demand (Kulik, 1999).

Advanced ceramics are produced from three main classes of materials, namely oxides, carbides, and nitrides, with a small quantity accounting for mixed compounds (World Advanced Ceramics, 1966). Japan has been at the forefront for a number of years, owing partly to the high degree of cooperation between companies in investigations and developments (dynamic partnership) and high export volumes (Kulik, 1999; Charreyron, 2013). The major volume of production in Japan is represented by electronic ceramics, accounting for up to $80 \%$ of total production (Kulik, 1999). The second largest producer of advanced ceramics is North America, where the industry has been driven by massive government financing of research and design development. The main difference between the two approaches is that North America plays a leading role in technology and Japanese companies lead in the applications of advanced ceramics. Such approaches have been successfully adopted by a number of European countries that now contribute extensively to the advanced technology market. One such country is Germany, which is home to a number of companies that compete for advanced technology projects throughout the world.

\section{Advances in research and development of advanced ceramics}

One of the most significant advances in ceramics research in the past two decades has been improvements in fracture toughness, especially for structural ceramics. On a comparative basis, glass has a fracture toughness of 1 MPa.m 0.5 and most conventional ceramics range from about 2-3 MPa.m0.5; steel is about 40 MPa.m0.5 (Freitag and Richerson, 1998). Some advanced ceramics such as transformation toughened zirconia- $\mathrm{ZrO}_{2}$ have toughness of about $15 \mathrm{MPa}$.m 0.5 , which is higher than that of tungstencarbide cobalt (WC-Co) cermet and cast iron (Freitag and Richerson, 1998). This has dramatically improved the resistance to contact stress and handling damage, thus imparting high reliability and durability comparable to that of metals and WC-Co cermets (Freitag and Richerson, 1998). Prior to 1970, most ceramic materials had strengths well below $345 \mathrm{MPa}$, but nowadays advanced ceramics such as silicon nitride $\left(\mathrm{Si}_{3} \mathrm{~N}_{4}\right)$ and toughened zirconia $\left(\mathrm{ZrO}_{2}\right)$ are commercially available with strengths above $690 \mathrm{MPa}$ (Freitag and Richerson, 1998).

The detailed mechanism of transformation toughening can be found elsewhere (Matizamhuka, 2016). However, what is important to note is that fracture toughness values 3-6 times higher than monolithic $\mathrm{ZrO}_{2}$ ceramics have been achieved by transformation toughening. Several other techniques have been developed over the years to improve fracture toughness of advanced ceramics, such as the use of more ductile binders and reinforcement with fibres, whiskers or second-phase particles. Details of such techniques can be found in the open literature (Matizamhuka, 2016).

On the other hand, the high cost of ceramic components has been attributed to the lack of large-scale production with minimum losses in the production line. Ceramic-based materials often compete against engineering materials with lower upfront costs, and it is often difficult to convince customers to pay a premium in exchange for performance benefits (Charreyron, 2013). Design, process technology, and machining technology still need to develop significantly to achieve cost-effective levels of high-volume production, consequently reducing the cost of components. A strategy used by previous market pioneers is that of forward pricing and continued government subsidies in anticipation of future market growth. The recent phenomenal growth in the advanced ceramics industry could easily translate into a greater market share in future, but this can happen only if major breakthroughs are achieved in fundamental and applied research (Liang and Dutta, 2001).

It is often considered that most new technologies arise from fundamental research and can be disconnected from social or market needs (Charreyron, 2013). History has proven that it may take decades for basic science to be translated into applied research. However, the majority of new business development cycles actually start with the onset of applied research programmes (Charreyron, 2013). Furthermore, applied research becomes active only when government-sponsored research such as in public institutions (addressing socioeconomic needs) meets private research and development, which is profit-driven. New business development requires effective coordination of public and private research and development policies (Charreyron, 2013). Such efficient coordination is clearly exemplified by the industry roadmap of the Japanese Ministry of International Trade and Industry (MITI) for the advancement of advanced ceramic materials in non-military domains (Charreyron, 2013). Clearly, research in advanced ceramics is one strategic project that South Africa can easily pursue to fulfil some of her visions as stipulated in the government's National Development Plan 2030 (National Planning Commission, 2013). South Africa is endowed with some of the world's largest reserves of natural resources, some of which are used as raw materials in the development of advanced ceramics. However, there are a limited number of locally owned facilities (if any) within South Africa involved in the manufacture of advanced ceramic components. A clear strategy here is the development of downstream value- 


\section{Advanced ceramics - the new frontier in modern-day technology: Part I}

addition manufacturing plants for advanced ceramic components, coupled with technology transfer through bilateral agreements with strategic partner countries with the requisite knowledge.

\section{Applications of advanced ceramics}

Superior material manufacturing technology and unique product attributes are crucial to the success of advanced ceramics. Advanced ceramics have demonstrated phenomenal performance under severe conditions in a number of applications, which include wear-related applications, transport, energy and the environment, health, hightemperature, and electronic applications. The most commonly used ceramic materials are alumina, zirconia, silicon nitride, silicon carbide, ferrite, and titanates. Below is a brief overview of some of the most common applications of advanced ceramics, highlighting how they have developed over the years. The list is not meant to be exhaustive but aims to give a qualitative review of the applications of the most popular advanced ceramic materials.

\section{Wear-related applications}

Advanced ceramics have surpassed cemented carbides in cutting tool applications due to their greater hot hardness and strength, which enables high-speed and efficient machining (Kuzler, 2012). Metal machining or finishing operations require a tool with a combination of properties such as high fracture toughness and hot hardness, thermal shock resistance, and chemical stability (Greil, 2002). In cutting applications, the key factors are the life of the cutting tool and the cutting speed (Freitag and Richerson, 1998). During cutting of hard metals such as cast iron and high-temperature superalloys, high temperatures are generated at the toolworkpiece interface, resulting in decreased tool life and cutting speed. Thus the use of advanced ceramics in cutting applications (Figure 1) is more cost-effective owing to the high removal rate during cutting, which increases production rates, decreases flank wear of the tool tips, and gives the capability to cut difficult-to-machine materials. The ideal machining temperatures for Ni-based superalloys of approximately $1200^{\circ} \mathrm{C}$ can only be accommodated by ceramic cutting tools (Kuzler, 2012). Traditionally-used WC-Co inserts wear rapidly at high temperatures, thus limiting the cutting speed to $121.6 \mathrm{~m} / \mathrm{min}$ (Freitag and Richerson, 1998). However, the use of silicon nitride $\left(\mathrm{Si}_{3} \mathrm{~N}_{4}\right)$ has demonstrated cutting speeds as high as $1520 \mathrm{~m} / \mathrm{min}$ at a depth cut of $5 \mathrm{~mm}$ and feed rate of $0.4 \mathrm{~mm}$ per revolution, under severe conditions with operating temperatures of up to $1100^{\circ} \mathrm{C}$ (Freitag and Richerson, 1998), with a dramatic effect on manufacturing output.

Alumina $\left(\mathrm{Al}_{2} \mathrm{O}_{3}\right)$ has been the lowest cost highperformance ceramic for many years, owing to the large quantities produced. Alumina is mainly used for roughing and finishing applications of cast and gray irons (Kuzler, 2012). $\mathrm{Si}_{3} \mathrm{~N}_{4}$ exhibits high fracture toughness and is used in interrupted machining applications, which are more prone to fracturing (Kuzler, 2012). The silicon carbide (SiC) family of materials is now well-established in the market. Some of the most attractive characteristics are superior wear resistance and high temperature capability compared to $\mathrm{Al}_{2} \mathrm{O}_{3}$ and $\mathrm{Si}_{3} \mathrm{~N}_{4}$. However, $\mathrm{SiC}$ is more expensive than $\mathrm{Al}_{2} \mathrm{O}_{3}$ and has a lower toughness than $\mathrm{Si}_{3} \mathrm{~N}_{4}$, thus it is not the optimum material for all wear applications.

A major breakthrough in the advanced ceramics industry was achieving high strength and toughness through microstructural manipulations, as mentioned earlier (Freitag and Richerson, 1998). Composite cutting tools such as SiC whisker-reinforced alumina $\left(\mathrm{SiC}_{\mathrm{w}} / \mathrm{Al}_{2} \mathrm{O}_{3}\right)$ have been commercialized and have found a niche in machining difficult materials such as Ni-based superalloys in the gas turbine industry, as well as wear components in the ceramic/metal hybrid tooling and dies in the canning industry for cupping, drawing, ironing, and can necking. The main drivers of advanced ceramic inserts include greater application in the finishing of hard-to-machine materials after roughing with carbide tools (Kuzler, 2012). This requires tools of finer grain size $(<100 \mathrm{~nm})$, which leads to fine cutting edges and improved tool wear resistance (Kuzler, 2012).

\section{Transport industry}

A number of commercial applications for advanced ceramics have been realized in the automotive industry. Several components manufactured from advanced ceramics are regarded as being more suited to meeting future emission regulations and improving fuel economy, owing to their lower weight, durability, and lower cost. There are a number of components being produced for the automotive industry, including $\mathrm{Si}_{3} \mathrm{~N}_{4}$ fuel injector links and high-pressure pumping plunges, $\mathrm{ZrO}_{2}$ injector metering, exhaust gas particle filters, bearings, and low-weight, high coefficient of friction ceramic composite brakes (Mandler, 2001; Gadow, 2001; Greil, 2002) (Figure 2). Ceramic composite brakes have been used in the luxury car market since 2001, and it is expected that more applications will emerge as costs are reduced (Griel, 2002).

A number of advantages have been realized through the use of advanced ceramic components such as ceramic multilayer piezoelectric actuators in high-pressure common rail (CR-series) fuel injection diesel engines (Greil, 2002). This has resulted in improved ignition operation and consequently reduced noise and decreased pollutant emissions (Greil, 2002). Another merit is the improved thermal efficiency from about $40-42 \%$ in conventional engines to about $65 \%$ for turbo diesel engines equipped with heat insulating ceramic components in the combustion chamber and exhaust manifold (Greil, 2002). There has been extensive use in the development of lightweight spacecraft capable of operating at

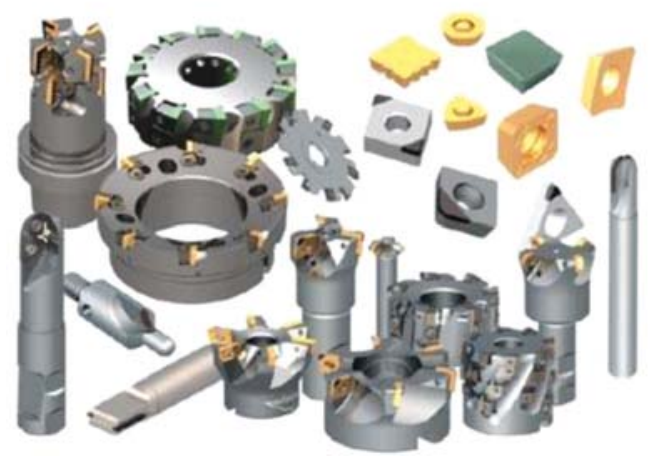

Figure 1-Schematic representation of cutting tool inserts made from different ceramic materials (source: Sandvik) 


\section{Advanced ceramics - the new frontier in modern-day technology: Part I}

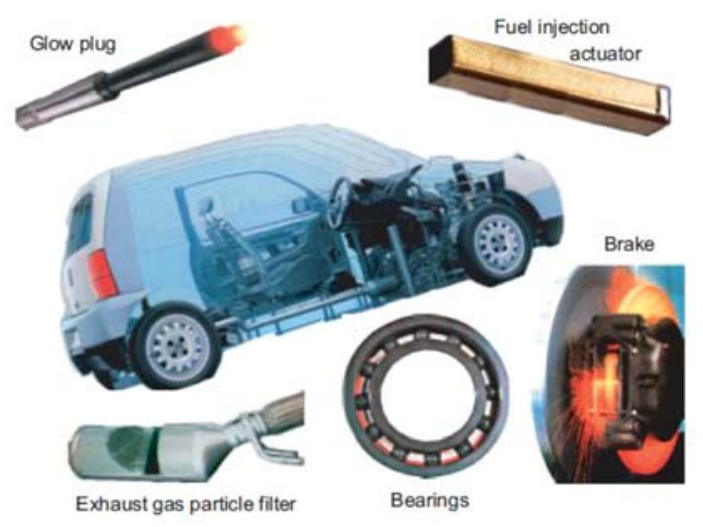

Figure 2-An illustration of various ceramic components that are used in modern automobiles (Greil, 2002)

temperatures up to $1600^{\circ} \mathrm{C}$, and silicon-carbide-based composites have been used for this application (Greil, 2002).

Over the last few decades the use of diesel engines has been on the rise in the developed countries. This is attributed to the excellent efficiencies achieved by these engines. Diesel engines find wide use in heavy-duty vehicles, agricultural and mining machinery, and stationary equipment. Since the beginning of the 21 st century, purification of diesel engine exhaust emissions has become a priority owing to environmental legislation. In the $\mathrm{EU}$, for instance, it is mandatory for all new vehicles to be equipped with highefficiency diesel particulate filters (DPFs, Figure 3) in combination with $\mathrm{NO}_{\mathrm{x}}$ reduction systems (Adler, 2005; Adler and Petasch, 2013). The driver behind this is the health concerns associated with fine and ultrafine diesel particulate matter (DPM) discharged in the atmosphere as a result of incomplete combustion of diesel fuel (Adler, 2005; Adler and Petasch, 2013). Moreover, soot particles emitted from diesel engines have been found to contribute directly to the 'greenhouse effect', having 2000 times the effect of $\mathrm{CO}_{2}$ (based on mass) (Adler, 2005; Adler and Petasch, 2013). The materials used in the manufacture of DPFs must possess certain desirable properties such as mechanical stability at high temperatures, chemical resistance, low Young's modulus, low coefficient of thermal expansion (CTE), and high thermal conductivity.

Silicon carbide wall flow filters have been used in light motor vehicles since the year 2000 (Adler, 2005; Adler and Petasch, 2013). By the end of 2006 approximately 6-9 million silicon carbide filters were being manufactured per year (Adler, 2005; Adler and Petasch, 2013). Aluminium titanate filters were introduced as a standard in passenger vehicles in 2006 (Adler, 2005; Adler and Petasch, 2013). On the other hand, cordierite has been extensively used in medium- to heavy-duty vehicles (Adler, 2005; Adler and Petasch, 2013). DPFs have become a billion dollar business in the few years since their inception and a bright outlook has been forecast, especially in Western Europe and North America (Adler, 2005; Adler and Petasch, 2013). Over the long term, the market for heavy-duty diesel engines is expected to rise, with the passenger vehicle market being dominated by alternative drive technologies, i.e. hybrid drives, fuel cells, and electric vehicles (Adler, 2005; Adler and Petasch, 2013).

\section{Energy}

The development of solid oxide fuel cells (SOFCs) as future sources for clean pollutant-free energy is a major breakthrough in the energy industry (Greil, 2002). SOFCs generate electricity and heat at high efficiencies with low levels of $\mathrm{NO}_{\mathrm{x}}$ and $\mathrm{SO}_{\mathrm{x}}$ emissions. (Greil, 2002). SOFCs utilize rapid ionic conductivity of either $\mathrm{O}_{2}^{2-}$ or protons, which allows charge transport across a solid oxide electrolyte/membrane, thus generating electrical energy (Riedel, Ionescu, and Chen, 2008). The oxidation and reduction reactions occur on either side of the solid oxide membrane/electrolyte through the consumption of $\mathrm{O}_{2}$ and fuel $\left(\mathrm{H}_{2}\right.$ or hydrocarbons) (see Figure 4).

The solid electrolyte is in the form of a ceramic with special properties to enable ionic conductivity; typically, yttria-stabilized zirconia with a $\mathrm{Ni} / \mathrm{ZrO}_{2}$ composite anode and $\mathrm{LaMnO}_{3}$ cathode has been used. This has become a multimillion dollar industry with big conglomerates involved in the production of pressurized hybrid SOFC power generation systems up to $250 \mathrm{~kW}$ (Greil, 2002).

The use of advanced ceramics extends to battery technology for the construction of electrodes such as lithium oxides in Li-ion batteries (Nemoto, 2003). For practical purposes, the Li-ion battery offers greater advantages over other types owing to its light weight per unit stored energy, and high ionization potential, energy, and power densities. Lithium is normally used combined with transition metal

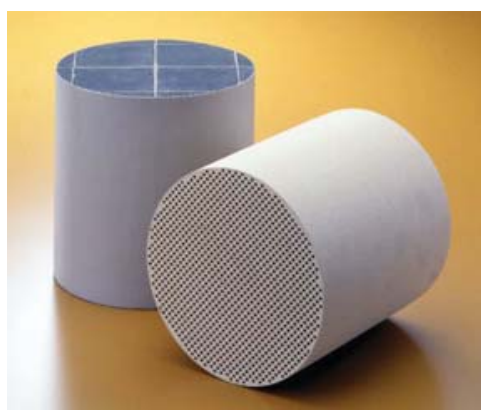

Figure 3-Diesel particulate filters (DPFs) made from SiC (left) and cordierite (right) produced by NGK Japan

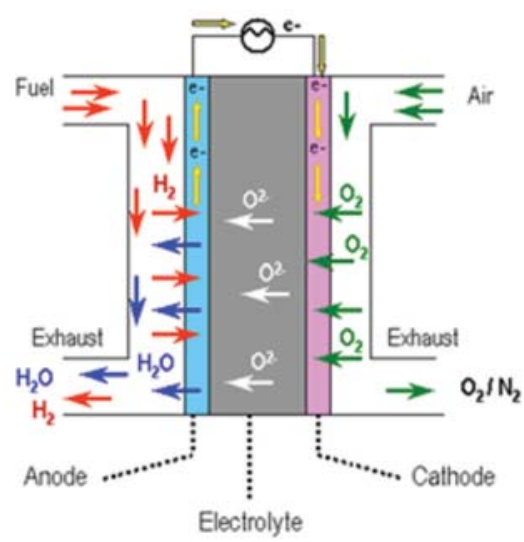

Figure 4-A schematic representation showing the working principle of a solid oxide fuel cell 


\section{Advanced ceramics - the new frontier in modern-day technology: Part I}

oxides (due to the high reactivity of $\mathrm{Li}$ ) coupled with a carbon electrode (Nemoto, 2003). Typically, $\mathrm{LiCoO}_{2}, \mathrm{LiMn}_{2} \mathrm{O}_{4}$, $\mathrm{LiFeO}_{2}$, and $\mathrm{LiFePO}_{4}$ have been used as positive active ceramic materials to generate a voltage range of 3.5-4 V (Nemoto, 2003). Since its inception in 1992, the Li-ion battery has found wide use in portable cellphones and laptop computers, with a typical capacity of 2 Ah (Nemoto, 2003). Larger capacity cells (100 Ah) have been developed for electrical energy storage and electric vehicle markets. In energy storage applications, the energy density is of great importance to minimize the space required for installation (Nemoto, 2003).

Energy generation systems such as gas turbines and diesel engines make use of advanced ceramic coatings as thermal barriers to improve operating efficiencies, service intervals and lifetimes, and fuel economy. These coatings are applied extensively on turbine parts to coat transition pieces, combustion liners, first stage blades and vanes, and in aerospace applications (Riedel, Ionescu, and Chen, 2008). Zirconia-based materials are used most frequently because they fulfil the basic requirements such as high melting point, no phase transformation from room temperature to the operating temperature, thermal expansion match with the substrate, good adherence to the substrate, low sintering rate of the porous microstructure, low thermal conductivity, and chemical inertness (Riedel, Ionescu, and Chen, 2008). However, these materials have a limited operating temperature for long-term applications (<1473 K), above which sintering occurs and phase transformation leads to cracking (Riedel, Ionescu, and Chen, 2008). Thus there is need to develop alternative ceramic materials for these applications.

\section{Environmental- and energy-related applications}

The oil crisis of the 1970s resulted in a sudden focus on the development of advanced energy-efficient engines with good fuel economy (Pompe, 1994). However these engines had to operate at higher temperatures than conventional engines. This led to the development of high-temperature ceramics capable of handling high temperatures without deterioration in their properties. The main material candidates are based on silicon carbide, silicon nitride, and partially stabilized zirconia (PSZ). In recent years, owing to the drop in energy prices and improved automotive technology, the demand for such ceramic components is greater in power generation applications (energy sector) such as stationary gas turbine parts (Pompe, 1994).

Advanced ceramics have a strong position in the area of environmental restoration, often coupled with energy-related issues. This type of application is primarily legislation-driven but can easily create the market pull to sustain stable growth once established (Pompe, 1994). The major application of advanced ceramics in the environmental industry is in hot gas filtration elements capable of operating at high temperatures (Greil, 2002). Such filters are used as catalyst support due to their high surface area, good mechanical properties and thermal shock resistance, and most importantly the ability to maintain such properties at elevated temperatures.A typical application is in catalytic converters, which are extensively used to remove $\mathrm{NO}_{\mathrm{x}}$ during hightemperature combustion of liquid or gaseous fuels.
The use of ceramic-type heat exchangers (Figure 5) capable of operating at temperatures of up to $1500^{\circ} \mathrm{C}$ in waste recovery applications has resulted in fuel savings of up to $50 \%$, compared to $20-30 \%$ for metallic alternatives (Pompe, 1994). Silicon carbide has been used extensively for this application due to its high wear resistance, corrosion resistance, erosion resistance, and high thermal conductivity.

Advanced ceramics also find use in photovoltaic modules which are used to harness the sun's energy, and ceramic bearings used in wind turbine generators to improve performance and durability. Ceramic insulators are key components of the fusion power plants (nuclear energy) envisioned in the future, and newer and lightweight materials are increasingly being used in wind turbine construction. Specially designed piezoelectric ceramics in the form of fibre composites are used in energy harvesting (EH) systems to reduce or eliminate the need for battery power, especially in remote locations, by utilizing energy from human and environmental sources (Cass et al., 2008). These devices have been utilized to power wireless sensors employing lowlevel environmental vibrations as a source of power, to recover waste energy from mechanical forces such as motion, vibration, compression, and tension (Cass et al., 2008). The voltage produced can be converted and stored in capacitors to continuously power electronic devices. To achieve this, a multi-disciplinary approach is required to leverage knowledge in several engineering fields (Cass et al., 2008).

\section{Electronic applications}

Owing to their unique properties, advanced ceramics can combine electrical insulation and magnetism, which is not achievable with metals (Riedel, Ionescu, and Chen, 2008). This makes them attractive for electrical applications as they can operate at high power and high frequencies, extreme temperatures, and under harsh environments (Riedel, Ionescu, and Chen,2008). Advanced ceramics in current use in such applications include silicon carbide in semiconductor devices used in power electronics, barium titanate $\left(\mathrm{BaTi}_{4} \mathrm{O}_{9}\right)$, zirconia titanate $\left(\mathrm{ZrTiO}_{4}\right)$, and other ceramics with simple and complex perovskite structures, which are used extensively in microwave applications due to their low dielectric loss and high permittivity (Riedel, Ionescu, and Chen, 2008).

Piezoceramics are widely used for electromechanical sensors and actuators (Riedel, Ionescu, and Chen, 2008). Their working principle is based on electrical and mechanical

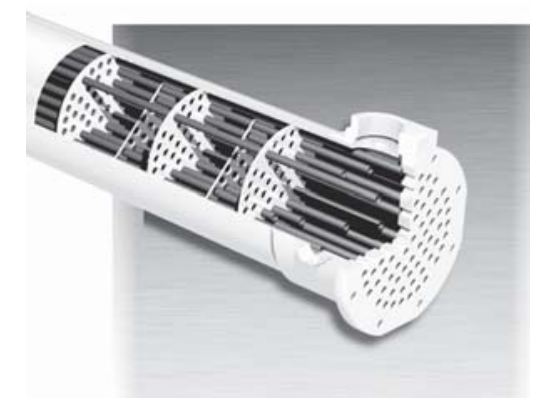

Figure 5-A diagram showing sintered $\mathrm{SiC}$ heat exchanger tubes for reliable high-temperature high-pressure chemical processing applications (source: Saint-Gobain) 


\section{Advanced ceramics - the new frontier in modern-day technology: Part I}

responses. For instance, when a mechanical force is applied an electrical response in the form of a voltage arises, the magnitude of which is normally proportional to the applied stress. Piezoceramics find extensive use in a wide range of applications which include automotive engineering for gas ignition, ultrasonic parking sensors, fuel level sensors, and wheel balancing transducers (Riedel, Ionescu, and Chen, 2008). Also, due to their ability to generate great ultrasonic intensities they are used as ultrasonic transmitters and receivers in signal and information processing applications (Riedel, Ionescu, and Chen, 2008).

Magnetic materials find extensive use in a number of modern technological applications such as in airconditioning, mobile phones, washing machines, loudspeakers, and electric motors (Abraham and Gupta, 2014). The magnets are required to have certain properties including high strength, corrosion resistance, and resistance to demagnetization due to excessive heat (Abraham and Gupta, 2014). Ceramic magnets were introduced in the 1950s and are the most popular permanent magnets today due to their low cost and the above mentioned properties (Abraham and Gupta, 2014). Non-conducting ceramic ferrites that are biased by a permanent magnet are used extensively for maintaining signal directionality in cellular base stations as isolators and circulators (Figure 7) (Abraham and Gupta, 2014; Hill, 2015). These devices direct radio frequency (RF) signals, at the same time preventing $\mathrm{RF}$ power from leaking into unwanted areas (Abraham and Gupta, 2014; Hill, 2015). The requirements for materials for such applications are quite stringent, i.e. the material has to be insulating, with low dielectric losses. This rules out metal magnetic materials and favours the oxide (ceramic) ferrites for such applications (Abraham and Gupta, 2014; Hill, 2015). The most widely used materials for such applications is yttrium iron garnet $\left(\mathrm{Y}_{3} \mathrm{Fe}_{5} \mathrm{O}_{12}\right)$.

Electromechanical devices constitute the largest market for permanent magnets and ceramic ferrites, and ceramic ferrites have the largest market share, estimated to have reached a usage of $900000 \mathrm{t}$ (valued at US\$4.5 billion) in 2013. This is projected to grow to $1.1 \mathrm{Mt}$ (valued at US\$6.6 billion) in 2018 .

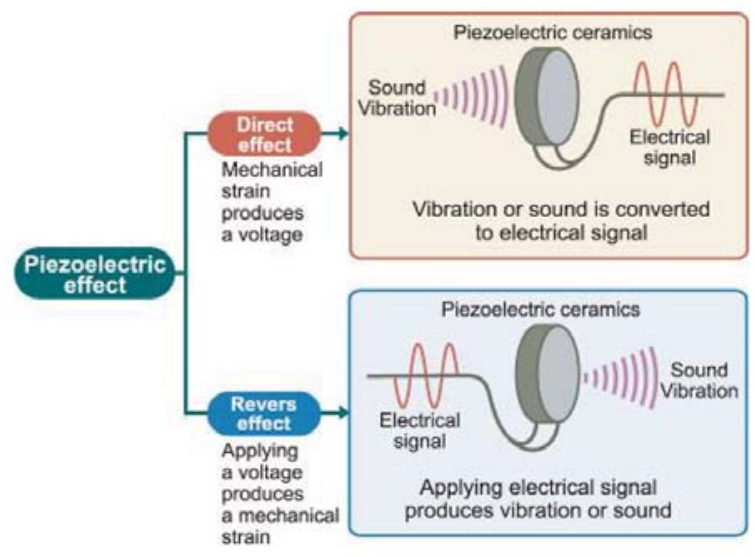

Figure 6-A schematic representation of the piezoelectric and reverse piezoelctric effect, showing areas where piezoceramics find use (Honda Eletronics Ltd)
In the last few decades, the rapid development of modern communication devices such as cellular telephones, antennae, and global positioning systems has energized research in microwave dielectric materials (Fillopovic, 2017). Dielectric ceramics are used widely in advanced electronic devices such as capacitors and microwave resonators. They are classified into two broad groups based on their dielectric properties. High quality factor materials are characterized by linear changes in polarization with applied electric field. This group is dominated by titanate-based materials, with typical examples such as $\mathrm{TiO}_{2}, \mathrm{MgTiO}_{3}, \mathrm{CaTiO}_{3}$, and $\mathrm{SrTiO}_{3}$ (Sakabe, 2003). This group is also characterized by a dielectric constant $\varepsilon_{r}$ of less than 1000 (Sakabe, 2003). The second group is characterized by materials possessing a dielectric constant $\varepsilon_{r}$ higher than 1000 (Sakabe, 2003). Typical examples include $\mathrm{BaTiO}_{3}$-based and lead-based dielectrics.

Thermoelectric (TE) ceramic materials can directly convert heat energy to electrical energy due to thermoelectric effects (Zhang and Zhao, 2015). The majority of thermoelectric devices operating near room temperature are based on bismuth telluride $\left(\mathrm{Bi}_{2} \mathrm{Te}_{3}\right)$ and its alloys (Zhang and Zhao, 2015).

This group constitute the largest market share of advanced ceramics and its growth is unmatched owing to the continuing advancement of the electronics sector.

\section{Health}

Advanced ceramics are increasingly used for prostheses due to a combination of excellent properties which include biocompatibility, wear resistance, stability, and strength (Riedel, Ionescu, and Chen, 2008). In 1970, a French orthopaedic surgeon successfully replaced the conventional stainless steel head of a hip joint with a high-density, highpurity sintered alumina joint (Kokubo, Kim, and Kawashita, 2003). The sintered alumina proved to possess superior properties such as mechanical strength, hardness, chemical durability, and hydrophilicity, and thus could offer a longer service life than conventional stainless steel orthopaedic devices. In February 2003, the US Food and Drug Administration approved the first ceramic-on-ceramic hip joint replacements. Since then, ceramic materials have been utilized in the manufacture of orthopaedic devices for hip

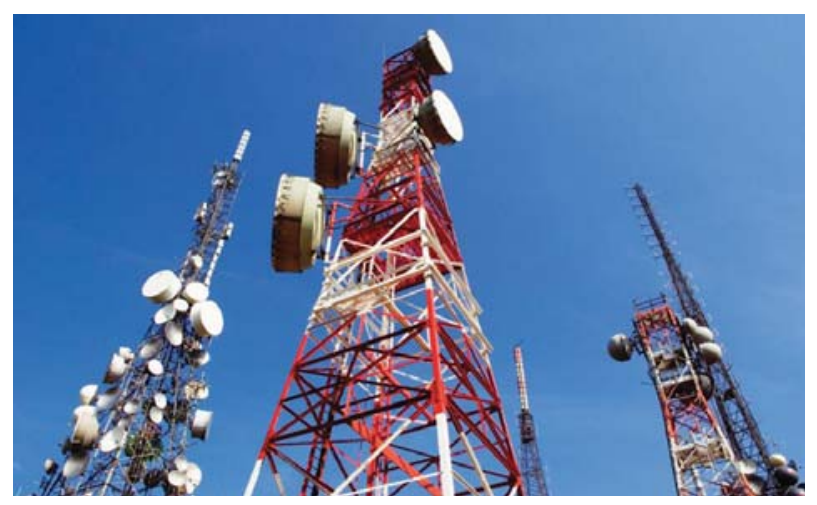

Figure 7-A schematic representation of a cellular base station showing the isolators and circulators where ceramic ferrites are used extensively (Hill, 2015) 


\section{Advanced ceramics - the new frontier in modern-day technology: Part I}

joint replacements and dental procedures, with alumina $\left(\mathrm{Al}_{2} \mathrm{O}_{3}\right)$ - and zirconia $\left(\mathrm{ZrO}_{2}\right)$-based ceramics topping the list (Kokubo, Kim, and Kawashita, 2003). The major drawback, however, is the lower fracture toughness values (approx. $2 \mathrm{MPa} . \mathrm{m}^{0.5}$ ) compared to bone (approx. $6 \mathrm{MPa} . \mathrm{m}^{0.5}$, which limits the applications of advanced ceramic materials to nonloaded bone replacements. This has prompted the development of reinforced ceramic matrix composites to obtain significantly superior fracture properties in comparison to monolithic ceramics (Kokubo, Kim, and Kawashita, 2003).

Over the last few decades it has been proven that ceramic materials can promote the regeneration of neighbouring tissue, can spontaneously bond to living tissues, and can locally destroy cancer cells to allow normal tissue regeneration after treatment (Kokubo, Kim, and Kawashita, 2003).

Zirconia is used extensively for dental restoration and was developed into a US\$700 million market within a period of less than 15 years (Charreyron, 2013). Zirconia offers significant benefits which include greater durability and the use of digital dentistry that saves time compared to veneer on precious metal castings technology. There are emerging technologies in other medical areas that are likely to create significant new markets for ceramic components, such as implantable devices used to regulate hearts and improve hearing (Charreyron, 2013). These ceramic implantables enable the use of wireless technologies to monitor the devices over the internet (Charreyron, 2013).

\section{Outlook}

The industrial revolution witnessed great advances in metal and alloy manufacture and has technically come of age, and it is believed that the 21 st century (sometimes referred to as the 'dot-com age' will depend on high-performance advanced ceramic materials. There is no doubt that advanced ceramic materials offer superior performance, are long-lasting, and perform crucial functions in a wide range of technological applications, and cannot be easily replicated by other engineering materials. Advanced materials almost always face high market-entry barriers, due mainly to the reluctance of designers and engineers to change from materials they are more familiar with, coupled with unfamiliarity to potential users, redesign requirements, and high cost of components.

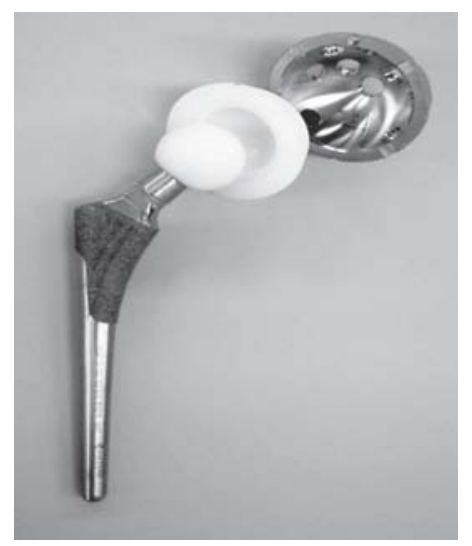

Figure 8-Alumina ceramic-on-ceramic component used for hip joint replacements (Kyocera Corp.)
The past few decades have seen the emergence of newer technologies which demand more advanced and higher performance engineering materials in a wide range of applications. Advanced ceramic materials have surpassed most traditional engineering materials and remain uncontested in a wide range of such applications. The phenomenal growth experienced is testimony to this. This has been driven mainly by the Asian markets, especially China and Japan. The African continent has yet to take part in the technological boom. Most African states still remain end-user markets for most of these technologies with little or no participation in the research and development of homegrown solutions to technologies requiring advanced ceramics. Infrastructural development programmes, coupled with economic growth on the African continent, are expected to drive new demand for advanced ceramics. The possibility of producing low-cost, mass-produced and high-profit-margin advanced ceramic products is, however, of major concern. The development efforts that have driven the initial boom are crucial for the sustainability of a profitable venture. There are already a number of private entities in the business that possess the technical capability to drive these technologies forward. Africa as a whole needs substantial investment in the development of home-grown solutions requiring advanced ceramics by partnering with institutions that already have the requisite knowledge.

\section{References}

ABraham, T. and GuPTA, B.L. 2014. Continued growth for ceramic-based and other permanent magnets. Advanced Ceramics.

https://www.ceramicindustry.com/articles/94215-continued-growth-forceramic-based-and-other-permanent-magnets

ADLER, J. 2005. Ceramic diesel particulate filters. International Journal of Applied Ceramic Technology, vol .2, no. 6. pp. 429-439.

AdLeR, J. and PetAsch, U. 2013. Diesel particulate filters. Handbook of Advanced Ceramics. Elsevier.pp.585-606.

CAss, R., Kim, H., Moнammadi, F., and RuddLE, J. 2008. Clean energy through ceramics. Advanced Ceramics. https://www.ceramicindustry.com/ articles/88949-special-section-advanced-ceramics-clean-energy-throughceramics

Charreyron, P. 2013. Time-to-market. Advanced Ceramics. https://www.ceramicindustry.com/articles/93164-advanced-ceramicsmarket-development

Filipović, S., Pavlović, V.P., Obradović, N., V. Paunović, Maca, K., and Pavlović, V.B. 2017. The impedance analysis of sintered $\mathrm{MgTiO}_{3}$ ceramics. Journal of Alloys and Compounds, vol. 701. pp. 107-115. https://www.infona.pl/ resource/bwmeta1.element.elsevier-f1133cd1-d25b-3acc-85adbf $42714 \mathrm{e} 65 \mathrm{c} 6$

FreitAG, W. and Richerson, D.W. 1998. Opportunities for advanced ceramics to meet the needs of industries of the future. US Advanced Ceramics and Oak Ridge National Laboratory. US Department of Energy DOE/ORO 2076. pp. $1-24$.

GADow, R. 2001.Ceramic Materials and Components for Engines. Wiley-VCH, Weinheim, Germany. p. 13.

GREIL, P. 2002. Advanced engineering ceramics. Advanced Materials, vol. 14, no. 10. pp.709-715.

HILL, M.D. 2015. Developing magnetic garnet ceramics for wireless infrastructure applications. Advanced Ceramic. https://www.ceramicindustry.com/articles/95167-developing-magneticgarnet-ceramics-for-wireless-infrastructure-applications

KокUво, T., KIM, H-M., and KaWASHITA, M. 2003. Ceramics for biomedical applications. Handbook of Advanced Ceramics. Somiya, S., Aldinger, F., Spriggs, R., Uchino, K., Koumoto, K., and Kaneno, M. (eds.). Elsevier. pp. 385-412.

KULIK, O.P. 1999 .Current state of development of new ceramic materials (review of foreign literature). Powder Metallurgy and Metal Ceramics, vol. 38, no. 1-2. pp .93-101. 


\section{Advanced ceramics - the new frontier in modern-day technology: Part I}

Kuzler, F. 2012. Advanced arena: why ceramic cutting tools? Advanced Ceramics. https://www.ceramicindustry.com/articles/92178-advancedarena--why-ceramic-cutting-tools-

LiAnG, Y. and DutTA, S.P. 2001. Application trend in advanced ceramic technologies. Technovation, vol. 21. pp. 61-65

MANDLER, W.F. and Yonushonis, T.M. 2001. Commercial applications for advanced ceramics in diesel engines. Proceedings of the 25th Annual Conference on Composites for Advanced Ceramic Material Structuring. Singh, M. and Kessen, T. (eds.). American Ceramic Society, Westerville, $\mathrm{OH}$.

MATIZAмнuкA, W.R. 2016. Spark plasma sintering (SPS) - an advanced sintering technique for structural nanocomposite materials. Journal of the Southern African Institute of Mining and Metallurgy, vol.116. pp. 1171-1180.

National Planning Commission, South Africa. 2013. National Development Plan Vision 2030. https://www.gov.za/sites/www.gov.za/files/devplan_2.pdf

Nемото, Н. 2003. Ceramic materials for energy systems. Handbook of Advanced Ceramics. Somiya, S., Aldinger, F., Spriggs, R., Uchino, K., Koumoto, K., and Kaneno, M. (eds.). Elsevier. pp. 355-365.

PompE, R. 1994. Some recent promising developments in industrial application of advanced technical ceramics. Transactions in Materials Research
Society of Japan, vol. 19B. pp. 709-718.

RIEDEL, R., Ionescu, E., and Chen, I-W. 2008. Modern trends in advanced ceramics. Ceramics Science and Technology. Wiley-VCH, Weinheim, Germany. pp.3-38.

Rothman, E.P., Schoenung, J.M., and ClaRK, J.P. 1987. Markets for advanced structural ceramics. Resources Policy, vol. 13, no. 2. pp. 123-141.

SAKABE, Y. 2003. Dieletric materials. Handbook of Advanced Ceramics. Somiya S., Aldinger, F., Spriggs, R., Uchino, K., Koumoto, K., and Kaneno, M. (eds.). Elsevier. pp. 161-179.

Taroco, H.A., Santos, J.A.F., Domingues, R.Z., and Matencio, T. 2011. Ceramic materials for solid oxide fuel cells. Advances in Ceramics-Synthesis and Characterisation, Processing and Specific Applications. InTech. pp. 423-446. https://www.intechopen.com/books/advances-in-ceramicssynthesis-and-characterization-processing-and-specificapplications/ceramic-materials-for-solid-oxide-fuel-cells

World Advanced Ceramics. 1966. Canadian Ceramics Quarterly, vol. 65, no. 1. pp. 21-22.

ZHANG, X. and ZHAO, L-D. 2015. Thermoelectric materials: energy conversion between heat and electricity. Journal of Materiomics, vol. 1. pp. 92-105.

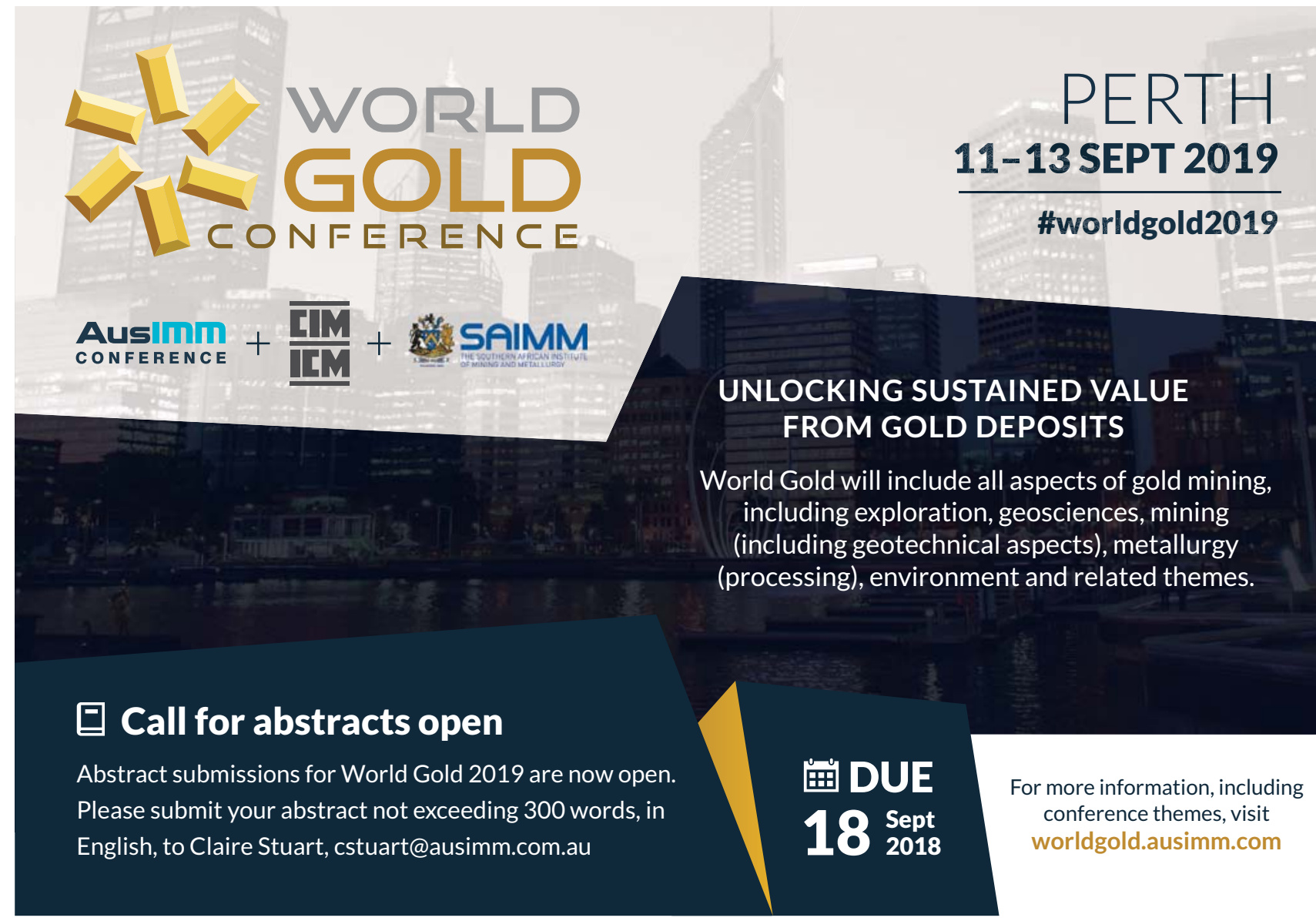

